\title{
Faktor-Faktor yang Berhubungan dengan Konsumsi Tablet Tambah Darah (TTD) pada Remaja Putri di Indonesia: Literatur Review
}

\author{
Nelda Amir ${ }^{1}$, Kusharisupeni Djokosujono ${ }^{2}$ \\ Pasca Sarjana Fakultas Kesehatan Masyarakat Universitas Indonesia ${ }^{1}$ \\ Departemen Gizi Universitas Indonesia ${ }^{2}$ \\ Pondok Cina, Kecamatan Beji, Kota Depok, Jawa Barat 12345 \\ nelda.amir@ui.ac.id
}

\begin{abstract}
Abstrak
Anemia Gizi Besi (AGB) mempunyai dampak yang serius, baik pada ibu hamil maupun pada remaja. Sangat penting mengatasi anemia pada remaja putri agar masalah anemia tidak berlanjut ketika hamil, salah satunya dengan mengonsumsi Tablet Tambah Darah (TTD) yang mengandung $60 \mathrm{mg}$ Fe elemental dan $0,4 \mathrm{mg}$ asam folat. Penelitian ini bertujuan untuk melihat faktor-faktor apa saja yang berhubungan dengan konsumsi TTD pada remaja putri di Indonesia. Studi penelitian ini adalah literatur review dengan mengekstrak semua penelitian di Indonesia tentang faktor-faktor yang berhubungan dengan konsumsi TTD pada remaja putri (11-19 tahun) di Indonesia. Hasil analisis menunjukkan bahwa faktor-faktor yang berhubungan dengan konsumsi TTD pada remaja putri di Indonesia yaitu dukungan guru $(\mathrm{p}=0,000$ $\mathrm{OR}=4,7)$, sikap $(\mathrm{p}=0,031 \mathrm{OR}=2,192)$, budaya $(\mathrm{p}=0,012 \mathrm{OR}=2,517)$, dukungan keluarga $(\mathrm{p}=0,029)$, perceived threat $(\mathrm{p}=0,02)$, perceived benefit $(\mathrm{p}=0,01)$, perceived barrier $(\mathrm{p}=0,02)$, dan self efficacy $(\mathrm{p}=0,00)$. Faktor yang tidak berhubungan yaitu pengetahuan, daya beli, ketersediaan, dukungan orang tua, pendapatan orang tua, perceived susceptibility (persepsi kerentanan), seriousness (keseriusan/keparahan). Faktor yang paling banyak diteliti yaitu tentang pengetahuan dan dukungan orang tua. Faktor-faktor yang berhubungan dengan kepatuhan remaja putri dalam mengonsumsi TTD di Indonesia yaitu dukungan guru, sikap, budaya, dukungan keluarga, perceived threat (ancaman yang dirasakan), perceived benefit (manfaat yang dirasakan), perceived barrier (hambatan yang dirasakan), dan self efficacy.
\end{abstract}

Kata kunci: konsumsi tablet tambah darah, remaja putri, anemia

\begin{abstract}
Abtract
Iron Deficiency Anaemia (IDA) has a serious impact on both pregnant women and teenage. It is very important to overcome anaemia in teenage girl so that the anaemia problem does not continue when pregnant, one of them is by consuming Iron Tablet (IT) which contains $60 \mathrm{mg}$ of element Fe and $0.4 \mathrm{mg}$ of folic acid. The research aimed to see what factors are associated with IT consumption in teemage girls in Indonesia. This research study is a review literature by extracting all research in Indonesia about factors related to IT consumption in teenage girls (11-19 years) in Indonesia. The result show that factors associated with IT consumption in teenage girls in Indonesia were teacher support ( $p=0,000$ OR $=4,7)$, attitudes $(p=0,031$ OR $=2,192)$, culture $(p=0,012$ OR $=2,517)$, family support $(p=0.029)$, perceived threat $(p=0.02)$, perceived benefit $(p=0.01)$, perceived barrier $(p=0.02)$, and self efficacy $(p=0.00)$. Unrelated factors are knowledge, purchasing power, availability, parents support, parental income, perceived susceptibility, seriousness. The most studied factors are about knowledge and parents support. Factors related to teenage girl adherence in consuming IT in Indonesia are teacher support, attitudes, culture, family support, perceived threat, perceived benefit, perceived barrier, and self efficacy.
\end{abstract}

Keyword: Consumption iron tablet, teenage girl, adolescent, anaemia. 


\section{Pendahuluan}

World Health Organization menyatakan bahwa lebih dari $30 \%$ penduduk di dunia mengalami anemia. Persentase pada negara maju sebesar 4,3-20\% dan pada negara berkembang sebesar $30-48 \%$ dengan anemia gizi besi. Secara global, sebesar 43\% diderita anak-anak, 38\% ibu hamil, $29 \%$ wanita tidak hamil, dan sebesar $29 \%$ semua wanita usia subur didiagnosa anemia ${ }^{1}$.

Di Indonesia, anemia karena kekurangan zat besi (Anemia Gizi Besi) merupakan salah satu masalah gizi yang belum selesai diatasi, baik pada ibu hamil maupun pada remaja. Berdasarkan data RISKESDAS tahun 2018 terjadi peningkatan anemia pada ibu hamil sebesar 11,8\% dibanding tahun 2013. Sebesar $37,1 \%$ ibu hamil menderita anemia pada tahun 2013 dan pada tahun 2018 sebesar 48,9\% ${ }^{2}$. Hal ini terjadi karena tingginya prevalensi anemia pada remaja putri yaitu sebesar $25 \%$ dan $17 \%$ pada WUS $^{3}$.

Anemia mempunyai dampak yang besar terhadap kesehatan terutama pada ibu hamil, ibu hamil dengan anemia akan mengakibatkan perdarahan pada ibu hamil, bayi lahir prematur, BBLR (Berat Badan Lahir Rendah), gangguan jantung, ginjal, dan otak bahkan bisa menyebabkan ibu meninggal saat persalinan ${ }^{4}$. Sedangkan anemia pada remaja dapat menghambat perkembangan psikomotor, merusak kinerja kognitif, dan kinerja skolastik ${ }^{5}$. Oleh sebab itu masalah anemia ini harus dapat dicegah dan diatasi ketika masih remaja karena remaja akan menjadi ibu hamil nantinya ${ }^{6}$.

Menurut WHO tahun 2011, satu dari tiga wanita yang tidak hamil pada hampir 500 juta orang wanita mengalami anemia yang disebabkan karena pemasukan zat besi yang tidak mencukupi. Remaja putri sangat rentan kekurangan zat besi karena menstruasi, pertumbuhan yang cepat, dan peningkatan kebutuhan zat besi jaringan ${ }^{7}$.

Pemberian TTD merupakan cara yang efektif untuk mengatasi masalah anemia, apabila dikonsumsi rutin akan terjadi peningkatan pada kadar $\mathrm{Hb}^{8,6}$. Selain itu menurut penelitian Falkingham et al (2010) menyebutkan bahwa konsumsi TTD dapat meningkatkan kosentrasi pada wanita dan remaja serta meningkatkan IQ pada penderita anemia ${ }^{9}$. Penelitian yang dilakukan oleh Deshmukh et al di India (2008) menyatakan bahwa TTD kurang memberi dampak jika diberikan ketika hamil trimester pertama dan disarankan agar mempunyai cadangan besi yang cukup ketika sebelum hamil $^{10}$.

Hal ini juga didukung oleh pemerintah dengan program pemberian suplemen tambah darah pada remaja putri sesuai dengan PERMENKES RI No. 88 tahun 2014 tentang standar TTD bagi wanita usia subur dan ibu hamil $^{11}$ dan Surat Edaran (SE) Kementerian Kesehatan RI No. HK.03.03/V/0595/2016 tentang Pemberian tablet tambah darah pada remaja putri dan wanita usia subur. Pemberian TTD ini umumnya dilakukan pada anak Sekolah Menengah Pertama (SMP)/sederajat dan Sekolah Menengah Atas (SMA)/sederajat ${ }^{3}$.

Berdasarkan RISKESDAS tahun 2018, didapatkan bahwa cakupan TTD yang diterima remaja putri sebesar $76,2 \%$, dari $76,2 \%$ tersebut sebanyak $80,9 \%$ mendapat TTD di sekolah (anak sekolah). Berdasarkan angka 80,9\% tersebut konsumsi TTD remaja putri $\geq 52$ butir 
Nelda Amir, Kusharisupeni Djokosujono. Faktor-Faktor yang Berhubungan dengan Konsumsi Tablet Tambah Darah (TTD) pada Remaja Putri di Indonesia: Literatur Review

DOI:

hanya $1,4 \%$, sedangkan $<52$ butir sebesar $98,6 \%{ }^{2}$. Berarti masih rendahnya kesadaran remaja putri akan pentingnya konsumsi TTD sebagai langkah untuk pencegahan anemia.

Banyak faktor yang menyebabkan remaja putri tidak mengonsumsi atau masih rendahnya konsumsi TTD. Oleh sebab itu penelitian ini untuk melihat faktor-faktor apa saja yang berhubungan dengan konsumsi TTD pada remaja putri di Indonesia berdasarkan jurnaljurnal atau penelitian yang telah diextract (disaring dan diringkas)

\section{Metode}

Studi penelitian ini adalah literature review, dimana jurnal-jurnal yang dipilih adalah semua penelitian yang mencakup dengan faktorfaktor yang berhubungan dengan konsumsi TTD pada remaja putri di Indonesia. Jurnal atau penelitian ini dipilih dengan menetapkan limit atau filter yaitu antara tahun 2013-2018 (lima tahun terakhir), format full text. Dengan kata kunci: konsumsi tablet tambah darah, remaja putri, anemia atau keyword: Consumption iron tablet, teenage girl, adolescent, anaemia.

Kriteria inklusinya adalah remaja putri umur 11-19 tahun, yang diteliti adalah faktorfaktor yang berhubungan dengan konsumsi TTD, penelitian dilakukan di Indonesia. Kriteria eksklusinya adalah faktor-faktor yang berhubungan dengan anemia. Literatur atau jurnal adalah jurnal-jurnal yang didapat dari website jurnal OJS (Open Journal System), kemudian diekstrak/disaring sesuai topik dan kriteria inklusi. Jurnal yang didapat terdiri dari jurnal Ners dan Kebidanan Indonesia, Jurnal Kesehatan Masyarakat (JKM), Jurnal Gizi Pangan, Jurnal Berkala Kedokteran, dan Jurnal Ners. Berikut jurnal- jurnal yang diperoleh sesuai topik penelitian, yaitu konsumsi TTD pada remaja putri:

Tabel 1. Ekstrak Jurnal Faktor-Faktor yang Berhubungan dengan Konsumsi Tablet Tambah Darah (TTD) pada Remaja Putri di Indonesia

\begin{tabular}{|c|c|c|c|c|c|}
\hline No & Penulis & Judul & Tujuan & Metode & Hasil \\
\hline 1 & $\begin{array}{l}\text { Lestari et al } \\
(2015)\end{array}$ & $\begin{array}{l}\text { Pengetahuan } \\
\text { Berhubungan } \\
\text { dengan Konsumsi } \\
\text { Tablet Fe Saat } \\
\text { Menstruasi pada } \\
\text { Remaja putri di } \\
\text { SMAN } \\
\text { banguntapan } \\
\text { Bantul }\end{array}$ & $\begin{array}{l}\text { Untuk } \\
\text { mengetahui } \\
\text { hubungan } \\
\text { antara } \\
\text { pengetahuan } \\
\text { dengan } \\
\text { konsumsi } \\
\text { tablet Fe saat } \\
\text { menstruasi } \\
\text { pada remaja } \\
\text { putri }\end{array}$ & $\begin{array}{l}\text { Cross } \\
\text { sectional }\end{array}$ & $\begin{array}{l}\text { Tidak ada hubungan } \\
\text { antara pengetahuan } \\
\text { dengan konsumsi tablet } \\
\text { Fe saat menstruasi pada } \\
\text { remaja putri di SMAN } 2 \\
\text { Banguntapan Bantul. }\end{array}$ \\
\hline 2 & $\begin{array}{l}\text { Risva et al } \\
(2016)\end{array}$ & 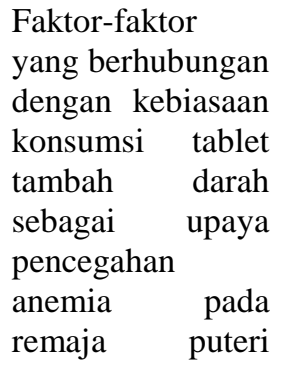 & $\begin{array}{l}\text { Untuk } \\
\text { mengetahui } \\
\text { faktor-faktor } \\
\text { yang } \\
\text { berhubungan } \\
\text { dengan } \\
\text { kebiasaan } \\
\text { konsumsi }\end{array}$ & $\begin{array}{l}\text { Case control } \\
\text { dengan } \\
\text { wawancara } \\
\text { dan } \\
\text { pengumpulan } \\
\text { data }\end{array}$ & $\begin{array}{l}\text { 1. Tidak ada hubungan } \\
\text { pengetahuan, daya } \\
\text { beli, ketersediaan } \\
\text { dengan kebiasaan } \\
\text { konsumsi tablet } \\
\text { tambah darah pada } \\
\text { remaja putri di } \\
\text { fakultas kesehatan } \\
\text { masyarakat }\end{array}$ \\
\hline
\end{tabular}




\begin{tabular}{|c|c|c|c|c|c|}
\hline No & Penulis & Judul & Tujuan & Metode & Hasil \\
\hline & & $\begin{array}{l}\text { (studi pada } \\
\text { mahasiswa tahun } \\
\text { pertama di } \\
\text { fakultas kesehatan } \\
\text { masyarakat } \\
\text { Universitas } \\
\text { Diponegoro) }\end{array}$ & $\begin{array}{l}\text { tablet tambah } \\
\text { darah. }\end{array}$ & & $\begin{array}{l}\text { Universitas } \\
\text { Diponegoro. } \\
\text { 2. Ada hubungan } \\
\text { sikap, budaya, } \\
\text { dukungan } \\
\text { lingkungan dengan } \\
\text { kebiasaan konsumsi } \\
\text { tablet tambah darah } \\
\text { pada remaja putri di } \\
\text { fakultas kesehatan } \\
\text { masyarakat } \\
\text { Universitas } \\
\text { Diponegoro. }\end{array}$ \\
\hline 3 & $\begin{array}{l}\text { Nuradhiani } \\
\text { et al (2017) }\end{array}$ & $\begin{array}{l}\text { Dukungan guru } \\
\text { meningkatkan } \\
\text { kepatuhan } \\
\text { konsumsi tablet } \\
\text { tambah darah } \\
\text { pada remaja putri } \\
\text { di kota Bogor }\end{array}$ & $\begin{array}{l}\text { Mengaji } \\
\text { penggunaan } \\
\text { kartu } \\
\text { monitoring } \\
\text { yang berbeda } \\
\text { serta faktor- } \\
\text { faktor yang } \\
\text { berpengaruh } \\
\text { terhadap } \\
\text { tingkat } \\
\text { kepatuhan } \\
\text { konsumsi } \\
\text { TTD pada } \\
\text { remaja putri. }\end{array}$ & $\begin{array}{l}\text { Quasi } \\
\text { experimental. }\end{array}$ & 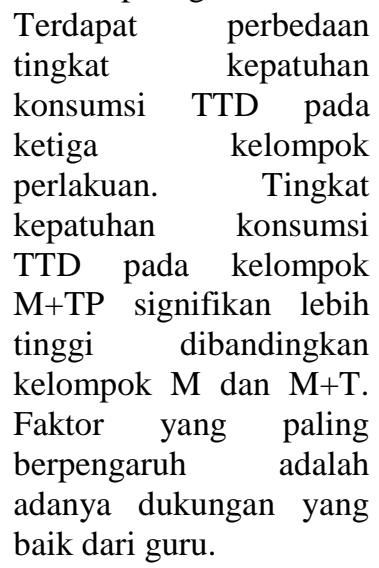 \\
\hline 4 & $\begin{array}{l}\text { Savitry et al } \\
(2017)\end{array}$ & $\begin{array}{l}\text { Hubungan } \\
\text { dukungan } \\
\text { keluarga dengan } \\
\text { niat konsumsi } \\
\text { tablet tambah } \\
\text { darah pada remaja } \\
\text { puteri }\end{array}$ & $\begin{array}{l}\text { Untuk } \\
\text { meneliti } \\
\text { hubungan } \\
\text { dukungan } \\
\text { keluarga } \\
\text { dengan niat } \\
\text { konsumsi } \\
\text { tablet tambah } \\
\text { darah pada } \\
\text { remaja putri } \\
\text { di SMA PGRI } \\
4 \\
\text { Banjarmasin. }\end{array}$ & $\begin{array}{l}\text { Cross } \\
\text { sectional }\end{array}$ & 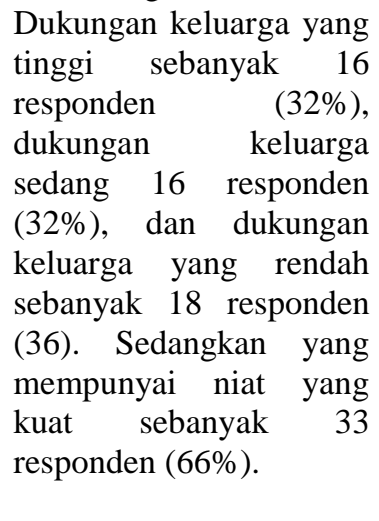 \\
\hline 5 & $\begin{array}{l}\text { Aprianti et } \\
\text { al (2018) }\end{array}$ & $\begin{array}{l}\text { Factors corelated } \\
\text { with the intention } \\
\text { of iron tablet } \\
\text { consumption } \\
\text { among female } \\
\text { adolescents }\end{array}$ & $\begin{array}{l}\text { Untuk } \\
\text { menganalisa } \\
\text { faktor-faktor } \\
\text { yang } \\
\text { berhubungan } \\
\text { dengan niat } \\
\text { konsumsi } \\
\text { tablet tambah } \\
\text { darah diantara } \\
\text { remaja putri } \\
\text { menggunakan } \\
\text { teori Health } \\
\text { Belif Model. }\end{array}$ & $\begin{array}{l}\text { Cross } \\
\text { sectional }\end{array}$ & $\begin{array}{lr}\text { 1. } & \text { Ada hubungan } \\
\text { antara } & \text { ancaman } \\
\text { yang dirasakan } & \text { threat), } \\
\text { (perceived } & \text { yang } \\
\text { manfaat rasan } & \\
\text { dirasakan } & \\
\text { (perceived benefit), } \\
\text { hambatan yang } \\
\text { dirasakan } \\
\text { (perceived barrier), } \\
\text { keyakinan } \\
\text { seseorang terhadap } \\
\text { kemampuannya } \\
\text { (perceived self } \\
\text { efficacy) dan niat } \\
\text { remaja putri untuk } \\
\text { konsumsi tablet } \\
\text { tambah darah. } \\
\text { Tidak ada hubungan } \\
\text { antara pendapatan }\end{array}$ \\
\hline
\end{tabular}


Nelda Amir, Kusharisupeni Djokosujono. Faktor-Faktor yang Berhubungan dengan Konsumsi Tablet Tambah Darah (TTD) pada Remaja Putri di Indonesia: Literatur Review

DOI:

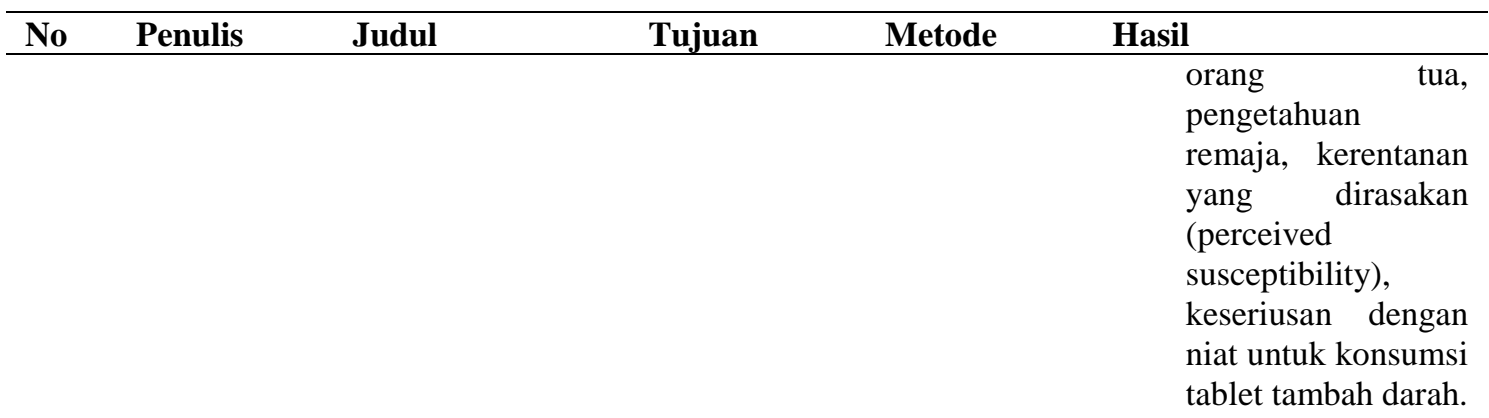

\section{Hasil}

Banyak faktor penyebab anemia gizi besi pada remaja putri antara lain karena meningkatnya kebutuhan zat besi pada saat remaja, kurangnya asupan zat besi pada makanan yang dikonsumsi, kehamilan pada usia remaja, penyakit infeksi dan infeksi parasit, sosial ekonomi, dan status gizi ${ }^{12}$. Salah satu cara yang paling cepat mengatasi anemia tersebut adalah dengan konsumsi TTD, yang sesuai dan didukung dengan permenkes nomor 88 Tahun 2014 dan surat edaran nomor HK. 03.03/V/0595/2016 tentang pemberian TTD pada remaja putri dan WUS. Namun, ada beberapa faktor yang berhubungan dengan konsumsi TTD tersebut, sehingga bisa mempengaruhi kepatuhan remaja putri untuk mengonsumsi atau tidak.

\section{Pembahasan}

\section{Hubungan pengetahuan dengan konsumsi TTD pada remaja putri.}

Berdasarkan lima penelitian yang didapat sebanyak empat penelitian meneliti hubungan pengetahuan dengan konsumsi TTD pada remaja putri. Penelitian pertama yang dilakukan oleh Lestari et al (2015) dengan metode survey melalui pendekatan cross sectional yang meneliti hubungan pengetahuan dengan konsumsi TTD pada remaja putri saat menstruasi di SMAN 2 Banguntapan Bantul, analisis data dengan menggunakan uji korelasi fisher exact. Hasil penelitian menyebutkan tidak ada hubungan pengetahuan dengan konsumsi TTD pada remaja putri saat menstruasi, baik remaja putri yang mempunyai pengetahuan tinggi maupun dengan pengetahuan rendah ${ }^{13}$.

Penelitian kedua oleh Risva et al (2016) menyimpulkan bahwa tidak terdapat hubungan antara pengetahuan dengan kebiasaan konsumsi TTD pada remaja putri $(\mathrm{P}=0,857)$. Penelitian ini dilakukan pada remaja putri tingkat satu di fakultas kesehatan masyarakat Universitas Diponegoro $^{14}$. Hal yang sama juga dinyatakan pada penelitian ketiga oleh Aprianti et al (2018) bahwa tidak ada hubungan pengetahuan remaja dengan niat untuk konsumsi TTD ${ }^{15}$.

Pada penelitian keempat oleh Nuradhiani et al (2017) juga menyimpulkan tidak ada hubungan pengetahuan gizi dengan kepatuhan konsumsi TTD pada remaja putri di kota Bogor $(\mathrm{p}=0,132)^{16}$. Sejalan dengan penelitian yang dilakukan di Pakistan yang menunjukkan tidak ada hubungan antara pengetahuan yang baik dengan kadar $\mathrm{Hb}^{17}$.

Penelitian-penelitian tersebut tidak sejalan dengan penelitian yang dilakukan oleh Hendrian Rian (2011) pada ibu hamil. Hasilnya 
menyatakan bahwa ada hubungan antara pengetahuan dengan perilaku ibu hamil dalam mengonsumsi TTD, bahkan pengetahuan adalah faktor yang paling dominan ${ }^{18}$. Begitu juga pada penelitian oleh Jalambo et al (2017) di Gazapalestina menunjukkan peningkatan pengetahuan setelah dilakukan intervensi pendidikan gizi yang dapat merubah sikap remaja putri terhadap anemia gizi besi ${ }^{19}$.

Pernyataan lain didapatkan bahwa, variabel pengetahuan ini mempunyai dua makna, pertama menyebutkan hubungan pengetahuan dengan konsumsi TTD adalah jika pengetahuan (informasi) seseorang tentang anemia dan TTD rendah maka prilaku konsumsi TTDnya juga rendah, berarti hal ini sangat dipengaruhi oleh pengetahuan/informasi yang diterima. Makna yang kedua, jika pengetahuan seseorang tinggi akan pentingnya TTD dalam pencegahan anemia namun pengetahuannya yang tinggi tersebut tidak diaplikasikan untuk mengonsumsi TTD. Hal ini mungkin dipengaruhi oleh faktor lain yaitu faktor yang berasal dari dalam diri seseseorang untuk menjaga kebiasaaan makan, penampilan, pemilihan dan arti makanan ${ }^{13}$.

\section{Hubungan dukungan guru dengan konsumsi TTD pada remaja putri.}

Berdasarkan lima penelitian yang didapat, bahwa satu penelitian meneliti hubungan dukungan guru dengan kepatuhan konsumsi TTD pada remaja putri di kota Bogor. Nuradhiani et al (2015) melakukan penelitian dengan menggunakan kartu monitoring serta faktor-faktor yang berpengaruh terhadap tingkat kepatuhan konsumsi TTD pada remaja putri. Hasilnya faktor yang paling mendukung keberhasilan kepatuhan remaja putri dalam mengonsumsi TTD dengan adanya dukungan dari guru karena selain waktu remaja putri lebih banyak dihabiskan di sekolah biasanya murid juga menjadikan mereka sebagai tokoh. Oleh sebab itu remaja putri atau anak sekolah lebih bisa menerima informasi dan mengikuti contoh yang disampaikan oleh guru dibandingkan pihak lain termasuk orang tua.

Sejalan dengan penelitian Mulugeta et al (2015) bahwa sekolah dan guru adalah tempat yang sangat mendukung remaja putri (anak sekolah) untuk bisa patuh mengonsumsi TTD. Diharapkan adanya kerja sama sektor kesehatan dan sektor pendidikan, dalam hal ini guru agar mendapatkan pelatihan tentang gizi. Selain itu penyuluhan gizi dapat disampaikan sebelum menyanyikan lagu kebangsaan di pagi hari ${ }^{6}$.

\section{Hubungan sikap dengan konsumsi TTD pada remaja putri.}

Berdasarkan lima penelitian yang diekstrak ada satu penelitian yang membahas antara hubungan sikap dengan kebiasaan konsumsi TTD. Dari hasil penelitian Risva et al (2016) didapatkan nilai $\mathrm{p}=0,031$ dan $\mathrm{OR}=2,192$ yang berarti responden dengan sikap yang baik memiliki kesadaran yang tinggi 2,2 kali untuk mengonsumsi TTD dibanding responden yg mempunyai sikap buruk ${ }^{14}$. Berbeda dengan penelitian di Pakistan (2015) didapatkan tidak ada hubungan antara sikap dengan kadar $\mathrm{Hb}$ $(\mathrm{p}=0,950)^{17}$.

\section{Hubungan daya beli dengan konsumsi TTD pada remaja putri.}

Berdasarkan tabel yang sudah diekstrak ada satu penelitian yang melihat hubungan daya beli terhadap tablet tambah darah dengan 
Nelda Amir, Kusharisupeni Djokosujono. Faktor-Faktor yang Berhubungan dengan Konsumsi Tablet Tambah Darah (TTD) pada Remaja Putri di Indonesia: Literatur Review

DOI:

kebiasaan konsumsi TTD yaitu pada penelitian Risva et al (2016) yang didapatkan nilai $\mathrm{p}=0,207$ yang artinya tidak terdapat hubungan antara daya beli terhadap TTD dengan konsumsi TTD pada remaja putri. Berdasarkan kuesioner dapat diketahui bahwa lebih dari separuh responden baik pada kasus maupun kontrol mampu membeli TTD atau daya beli terhadap TTD cukup baik sehingga daya beli tidak menjadi hambatan ${ }^{14}$ apalagi bagi remaja putri di sekolah bisa mendapatkan secara gratis dari program pemerintah melalui Dinas Kesehatan dan puskesmas.

\section{Hubungan ketersediaan dengan konsumsi TTD pada remaja putri.}

Sama halnya dengan daya beli, hubungan

ketersediaan juga diteliti oleh Risva et al (2016) dari lima jurnal yang ada. Hasilnya tidak ada hubungan antara ketersediaan TTD dengan konsumsi TTD pada remaja putri tahun pertama di Fakultas Kesehatan Masyarakat Universitas Diponegoro $(p=0,063)$. Hal ini disebabkan karena akses tempat mahasiswi tersebut di kota, dekat dengan pelayanan kesehatan dan toko obat atau apotek sehingga tidak ada masalah untuk mendapatkan TTD ${ }^{14}$.

Begitu juga pada siswi SMP dan SMA dengan mudah mendapatkan TTD secara gratis dari Dinas Kesehatan dan puskesmas sesuai program pemerintah melalui SE No. HK.03.03/V/0595/2016 tentang pemberian suplemen tambah darah pada remaja putri dan wanita usia subur yang merupakan kelanjutan dari PERMENKES RI No. 88 tahun 2014 tentang standar tablet tambah darah bagi wanita usia subur dan ibu hamil. Sejalan dengan penelitian Mulgeta et al (2015) di Tigray,

Ethiopia Utara menyebutkan bahwa TTD juga tersedia di fasilitas kesehatan (pusat kesehatan dan pos kesehatan) bagi remaja putri yang tidak sekolah ${ }^{6}$.

\section{Hubungan budaya dengan konsumsi TTD pada remaja putri.}

Hubungan budaya dengan konsumsi TTD juga diteliti oleh Risva et al (2016), satu dari lima penelitian yang diekstract. Ternyata nilai $\mathrm{p}=0,012$ dan $\mathrm{OR}=2,517$ yang artinya ada hubungan antara budaya dengan kebiasaan konsumsi TTD sebanyak 2,5 kali lebih besar dibandingkan remaja putri dengan budaya yang buruk. Budaya yang dimaksud adalah bahwa responden dari latar belakang pendidikan dan keluarga yang berbeda-beda sehingga juga mempunyai budaya yang beragam ${ }^{14}$.

\section{Hubungan dukungan lingkungan dengan konsumsi TTD pada remaja putri.}

Faktor lain yang diteliti adalah melihat hubungan dukungan lingkungan dengan konsumsi TTD pada remaja putri. Lingkungan dimaksud adalah semua orang yang ada di sekitar remaja putri seperti orang tua, teman sebaya, tetangga yang bisa mengajaknya untuk mengonsumsi $\mathrm{TTD}^{14}$.

Berdasarkan penelitian ada dua penelitian yang melihat hubungan dukungan lingkungan dengan konsumsi TTD. Pertama, penelitian dari Risva et al (2016) yang hasilnya menunjukkan $\mathrm{p}=0,003$ dan $\mathrm{OR}=3,133$, ini berarti terdapat hubungan lingkungan yang mendukung sebanyak 3,2 kali lebih besar dibandingkan dengan lingkungan yang tidak mendukung terhadap konsumsi TTD pada remaja putri, yaitu mahasiswi tingkat satu di fakultas kesehatan masyarakat Universitas Diponegoro. 
Kedua, penelitian oleh Savitry et al (2017) yang melihat hubungan dukungan keluarga dengan niat konsumsi TTD pada siswi di SMA PGRI 4 Banjarmasin. Hasilnya disimpulkan bahwa terdapat hubungan antara dukungan keluarga yang tinggi dengan niat yang kuat pada remaja putri dengan $\mathrm{p}=0,029$ $(\mathrm{P}<0,05)^{20}$. Kepatuhan remaja putri untuk mengonsumsi TTD dipengaruhi oleh orang lain seperti orang tua, pengetahuan orang tua yang baik tentang nutrisi dan akibatnya akan mendorong remaja putri untuk mengonsumsi TTD. Selain orang tua, dukungan lain dari masyarakat, tokoh agama, dan teman sebaya ${ }^{6}$.

Sejalan dengan penelitian Astuti Banar (2017) pada ibu hamil yang menyatakan ada hubungan dukungan suami dengan kepatuhan ibu hamil dalam mengonsumsi TTD $(\text { pvalue }=0,000)^{21}$. Berbeda dengan penelitian Nuradhiani et al (2015), didapatkan $\mathrm{p}=0,167$, yang artinya dukungan yang diberikan orang tua tidak membuat remaja putri untuk patuh mengonsumsi $\mathrm{TTD}^{16}$. Hal ini mungkin disebabkan orang tua hanya mengingatkan saja, tidak memantau secara penuh apakah TTD diminum oleh remaja putri.

\section{Hubungan pendapatan orang tua dengan konsumsi TTD pada remaja putri.}

Berdasarkan lima penelitian yang didapat, ada dua penelitian yang secara tidak langsung melihat hubungan antara pendapatan orang tua dengan konsumsi TTD pada remaja putri. Pada penelitian Nuradhiani (2015) dan Aprianti et al (2018) sama-sama menyimpulkan tidak ada hubungan antara pendapatan orang tua dengan konsumsi TTD pada remaja putri ${ }^{16,15}$. Berbeda dengan penelitian yang dilakukan oleh Sari et al
(2017) yang menyatakan bahwa ada hubungan pendapatan keluarga dengan kejadian anemia pada ibu hamil ${ }^{22}$.

Hubungan perceived threat, perceived benefit, perceived barrier, self efficacy, perceived susceptibility, dan seriousness dengan niat konsumsi TTD pada remaja putri.

Berdasarkan lima jurnal yang didapatkan, ada satu jurnal melihat hubungan berdasarkan teori health belief models. Teori health belief models tidak hanya melihat dari pengetahuan saja tapi bagaimana faktor-faktor pendukung lain yang mendorong seseorang mengambil suatu keputusan untuk kesehatannya. Adapun variabel yang diteliti oleh Aprianti et al (2018) adalah perceived threat, perceived benefit, perceived barrier, self efficacy, perceived susceptibility, dan seriousness dengan niat konsumsi TTD pada remaja putri SMA di Suarabaya.

Menurut Aprianti et al (2018), ada hubungan perceived threat atau ancaman yang dirasakan dengan niat konsumsi TTD pada remaja putri SMA di Surabaya $(\mathrm{p}=0,02)^{15}$. Sejalan dengan penelitian Setiyaningsih et al (2016), yang menyatakan ada hubungan langsung perilaku pencegahan hipertensi dengan ancaman $^{23}$.

Melihat hubungan perceived benefit atau manfaat yang dirasakan dengan niat konsumsi TTD pada remaja putri, hasilnya menunjukkan $\mathrm{p}=0,01$ yang artinya remaja putri yang merasa berguna atau bermanfaat terhadap TTD akan mempunyai niat yang kuat untuk mengonsumsi TTD tersebut ${ }^{15}$. Sejalan dengan penelitian Setiyaningsih et al (2016) yang menyatakan ada hubungan antara persepsi manfaat dengan perilaku pencegahan hipertensi ${ }^{23}$. 
Nelda Amir, Kusharisupeni Djokosujono. Faktor-Faktor yang Berhubungan dengan Konsumsi Tablet Tambah Darah (TTD) pada Remaja Putri di Indonesia: Literatur Review DOI:

Hubungan perceived barrier atau hambatan yang dirasakan dengan niat konsumsi TTD pada remaja putri SMA di Surabaya didapatkan $\mathrm{p}=0,02$, yang berarti ada hubungan antara tidak adanya hambatan yang dirasakan dalam mengonsumsi TTD dengan niat yang kuat untuk mengonsumsi TTD tersebut ${ }^{15}$. Sejalan dengan penelitian Kurniawati dan Sulistyowati (2014), yang hasilnya ada hubungan antara persepsi hambatan dengan dengan tindakan dalam mencegah keputihan patologis ${ }^{24}$.

Hubungan self efficacy atau keyakinan dari diri sendiri untuk mampu mengonsumsi TTD. Hasilnya menunjukkan ada hubungan antara self efficacy dengan niat yang kuat untuk mengonsumsi TTD pada remaja putri di Surabaya $(p=0,00)^{15}$. Hal ini Sejalan dengan penelitian Setiyaningsih et al (2016), yang menyatakan ada hubungan antara self efficacy dengan perilaku pencegahan hipertensi ${ }^{23}$.
Hubungan perceived susceptibility atau kerentanan yang dirasakan dengan niat konsumsi TTD. Hasilnya didapatkan tidak ada hubungan pada remaja putri yang merasakan kerentanan terhadap niat yang kuat untuk mengonsumsi TTD $(p=0,67)^{15}$. Berbeda dengan penelitian Kurniawati dan Sulistyowati (2014), yang menyatakan ada hubungan antara kerentanan yang dirasakan dengan tindakan pencegahan keputihan patologis ${ }^{24}$.

Aprianti et al (2018) juga melihat hubungan antara keseriusan (seriousness) pentingnya konsumsi TTD dengan niat konsumsi TTD, hasilnya menunjukkan tidak ada hubungan keseriusan pada remaja putri dengan niat yang kuat untuk mengonsumsi TTD $(\mathrm{p}=0,10)^{15}$. Hal ini tidak sejalan dengan penelitian Kurniawati dan Sulistyowati (2014) yang menyatakan ada hubungan antara keseriusan dengan tindakan pencegahan keputihan patologis ${ }^{24}$.

Tabel 2. Faktor-faktor yang berhubungan dengan konsumsi TTD pada remaja putri di Indonesia

\begin{tabular}{lcc}
\hline \multicolumn{1}{c}{ Variabel } & P value & OR (95\% CI) \\
\hline Dukungan guru & $0,000^{16}$ & $4,7(1,5-14,2)^{16}$ \\
Sikap & $0,031^{14}$ & $2,192^{14}$ \\
Budaya & $0,012^{14}$ & $2,517^{14}$ \\
Lingkungan (dukungan keluarga) & $0,029^{20}$ & - \\
Perceived trheat (ancaman yang dirasakan) & $0,02^{15}$ & - \\
Perceived benefit (manfaat yang dirasakan) & $0,01^{15}$ & - \\
Perceived barrier (hambatan yang dirasakan) & $0,02^{15}$ & - \\
Self efficacy & $0,00^{15}$ & - \\
\hline \multicolumn{2}{c}{ Sumber: Data Risva et al (2016), Nuradhiani et al (2017), Savitry et al (2017), Aprianti et al (2018). }
\end{tabular}




\section{Kesimpulan}

Ada banyak faktor yang menentukan hubungan konsumsi TTD pada remaja putri di Indonesia, baik faktor internal maupun faktor dari luar diri remaja tersebut. Berdasarkan lima penelitian yang diekstrak, faktor yang berhubungan dengan konsumsi TTD yaitu dukungan guru, sikap, budaya, lingkungan (dukungan keluarga), Perceived treat (ancaman yang dirasakan), Perceived benefit (manfaat yang dirasakan), Perceived barrier (hambatan yang dirasakan), dan self efficacy. Faktor-faktor yang tidak berhubungan adalah pengetahuan, daya beli, ketersediaan, dukungan orang tua, pendapatan orang tua, perceived susceptibility (kerentanan yang dirasakan), dan seriousness.

\section{Saran}

Agar konsumsi TTD pada remaja putri dapat optimal, maka diperlukan motivasi dan keyakinan yang kuat dalam diri remaja tersebut. Selain itu dibutuhkan dorongan dari luar seperti adanya dukungan guru dan lingkungan (keluarga), sehingga masalah anemia pada remaja putri di Indonesia dapat diatasi.

\section{Ucapan Terima Kasih}

Penulis mengucapkan terima kasih yang sebesar-besarnya kepada pembimbing dan dosen mata kuliah penulisan ilmiah dan publikasi Fakultas Kesehatan Masyarakat Universitas Indonesia.

\section{Daftar Pustaka}

1. WHO. The Global Prevalance of Anemia in 2011. Geneva; 2015.

2. Kemenkes RI. Hasil Utama RISKESDAS
2018. 2018;

3. Kementerian Kesehatan RI. Surat Edaran tentang Pemberian Tablet Tambah Darah pada Remaja Putri dan Wanita Usia Subur. Jakarta: Kemenkes RI; 2016.

4. Sinsin I. Masa Kehamilan dan Persalinan. Jakarta: PT Elex Media Komputindo; 2008.

5. Aulakh R. Adolescent Anemia: Risk Factors. 2016;

6. Mulugeta A, Tessema M, Kiday H, Seid O. Examining Means of Reaching Adolescent Girls for Iron Supplementation in Tigray, Northern Ethiopia. 2015;9033-45.

7. WHO. Guidelines: Daily Iron Supplementation in Adult Women and Adolescent Girls. Geneva; 2016.

8. Raghvendra G. Weekly Iron Folate Supplementation in Adolescent Girls - An Effective Weekly Iron Folate Supplementation in Adolescent Girls - An Effective Nutritional Measure for the Management of Iron Deficiency Anaemia. 2014;(May 2013).

9. Falkingham M, Abdelhamid A, Curtis P, Fairweather-tait S, Dye L, Hooper L. The effects of oral iron supplementation on cognition in older children and adults : a systematic review and meta-analysis. 2010;1-16.

10. P.R. Deshmukh, B.S. Garg and MSB. Effectiveness of Weekly Supplementation of Iron to Control Anaemia among Adolescent Girls of Nashik, Maharashtra, India. 2008;

11. Kementerian Kesehatan RI. Peraturan Menteri Kesehatan Republik Indonesia Nomor 88 tahun 2014 tentang Standar Tablet Tambah Darah bagi Wanita Usia Subur dan Ibu Hamil. 88 Jakarta; 2014.

12. Sandra Fikawati, Syafiq A, Veratamala A. Gizi Anak dan Remaja. Ed. 1. Depok: PT Rajagrafindo Persada; 2017. 348 hal.

13. Lestari P, Mulyani S. Pengetahuan Berhubungan dengan Konsumsi Tablet Fe Saat Menstruasi pada Remaja Putri di SMAN 2 Banguntapan Bantul. 2015; (September 2015):145-9.

14. Risva TC, Rahfiludin MZ. Faktor-Faktor 
Nelda Amir, Kusharisupeni Djokosujono. Faktor-Faktor yang Berhubungan dengan Konsumsi Tablet Tambah Darah (TTD) pada Remaja Putri di Indonesia: Literatur Review

DOI:

yang Berhubungan dengan Kebiasaan

Konsumsi Tablet Tambah Darah sebagai Upaya Pencegahan Anemia pada Remaja Putri (Studi pada Mahasiswa tahun Pertama di Fakultas Kesehatan Masyarakat Universitas Diponegoro). 2016;4(April):243-50.

15. Aprianti R, Sari GM, Kusumaningrum $T$. Factors Correlated with the Intention of Iron Tablet Consumption among Female Adolescents. 2018;13(1).

16. Nuradhiani A, Briawan D, Dwiriani CM. Dukungan Guru Meningkatkan Kepatuhan Konsumsi Tablet Tambah Darah pada Remaja Putri di kota Bogor. 2017;12(November):153-60.

17. Shahzad S, Islam K, Azhar S, Fiza S, Ahmed W. Impact of Knowledge, Attitude and Practice on Iron Deficiency Anaemia Status Among Females of Reproductive Age Group ( 20- 21-year-old ) Studying in Government Home Economics College. 2017;3(4):31-6.

18. Hendrian R. Faktor-faktor yang Berhubungan dengan Perilaku Ibu Hamil dalam Mengkonsumsi Tablet Besi (Fe) di Puskesmas Kadugede Kabupaten Kuningan Tahun 2011. Universitas Islam Negeri Syarif Hidayatullah Jakarta; 2011.

19. Marwan O. Jalambo, Abdul Karim
Norimah IAN. Improvement in Knowledge, Attitude and Practice of Iron Deficiency Anaemia among Iron-Deficient Female Adolescents after Nutritional Educational Improvement in Knowledge , Attitude and Practice of Iron Deficiency Anaemia among Iron-Deficient Female Adole. 2017; (January).

20. Savitry NSD, Arifin S, Asnawati. Hubungan dukungan keluarga dengan niat konsumsi tablet tambah darah pada remaja puteri. 2017;029:113-8.

21. Astuti B. Hubungan Dukungan Suami dengan Kepatuhan Ibu hamil dalam Mengonsumsi Tablet Tambah Darah (Fe) di Puskesmas Garung. 2017;

22. Septi Indah Permata Sari, Aris Noviani, Rr. Sri Nuriyaty Masdiputri NI. Relationship of Education, Family Income, Compliance, and Procedure Consumption of Iron Tablet to Anemia among Pregnant Women. 2017;(2001):210-5.

23. Setiyaningsih R, Tamtomo D, Suryani N. Health Belief Model: Determinantsof Hypertension Prevention BehaviorinAdults at Community Health Center, Sukoharjo , Central Java. 2016;1:161-71.

24. Cici Kurniawati MS. Aplikasi Health Belief Models dalam Pencegahan Keputihan Patologis. 2014;2:117-27. 